\title{
The Influence of Tax Burden on the Profit of Banks in Conditions of Monopolistic Competition: Economic-Mathematical Modeling
}

Hossein Mazloumfard

Chief auditor, Ministry of finance and economic affairs, Iran.

\section{Volodymyr Glans}

$\mathrm{PhD}$, Vice President for Legal Affairs and Audit, Concern «NICMAS», Ukraine.

\begin{abstract}
The article formalized the effect of income taxation of banks on the basic characteristics of their activities. The necessary actions to achieve this goal is developing an econometric model which involves maximizing the bank's total profit after tax, and variable interest rate on deposits and loans, as well as the tax rate on profit. The system of limitations are formed in solving the tasks, namely: summary of balance sheet assets must equal its liabilities; should be done legislatively established requirements for capital adequacy. The conducted study allowed to formalized the impact of the rate of tax on bank profits on deposit and lending rate, which is the basis for countercyclical tax regulation of banking activity by differentiating the rate of income taxation of banks depending on the phase of the economic cycle: at stages of recovery in order to contain the possible credit boom and the emergence financial imbalances should reduce the tax rate, given that this leads to an increase in the cost of loans and a decrease in demand for deposit other services due to cheapening of their value. At the downside, on the contrary, it is necessary to increase the rate of this tax in order to stimulate cheapening of credit resources and increase the value of deposits.
\end{abstract}

Keywords: tax burden, profit ability of the bank, economic-mathematical modeling. JEL Classification: G21.

(C) The Authors, 2017. This article is published with open access at Sumy State University.

\section{Introduction}

Nowadays the research of tax problems is of particular relevance for the economy of any country, as the activation of globalization and integration processes at the supranational level leads to changes in the role and significance of individual economic entities in the system of economic relation, which quite naturally cause complication of the architecture of the financial system and the nature of the interaction between the entities within the framework of its separate structural elements. This requires from the state authorities the formation of an adequate concept of regulation of the activities of business entities that would meet the current conditions for the construction and functioning of the world economy. The expediency of developing and implementing a specific scheme for taxation of banks is due to the fact that banks have very specific reporting (and, according, the mechanism of formation of profit before taxation), which determines their differences from ordinary business entities. According, the application of tax scheme similar to other companies to banks can leads to changes in the value of supply and demand for a banking product, which, in turn, can leads to significant fluctuations in the price of services for the banking sector.

However, it is fair to note that banks are the main sources of borrowed financial resources for other entities, and therefore significant volatility in the banking sector may cause a destabilization of the economy as a whole and cause a decline in GDP growth or even a recession. In addition, banks contributed to the stable development of enterprises, and therefore, the problem of tax regulation of banks is extremely relevant in the context of the state policy towards effective formation of the revenue part of the budget.

Theoretical and practical aspects of the effect of the tax burden on the profit ability of the banks' activities were reflected in the scientific works of foreign scholars, in particular: D. Baker, B. Jetina, D. Dillon, M. Kin, D. Tobin, M. Sherman, S. Schulmeister and other.

The purpose of the article is to justify the impact of taxation on the basic parameters of banking activity by formalizing the dependence of interest rate on loans and deposits of the bank on the profit tax rate as the basis of counter-cyclical tax regulation of banking activity by differentiating rate of this tax depending on the phase of the development cycle of the country's economy. 


\section{Methods and Results}

The main tax burden on the banking sector as a whole, and every bank, in particular, is formed at the expense of paying income tax. At the same time, we note that the particularities of the impact of this tax on the activities of banks will be significantly different from other entities, since these financial intermediaries inherent not only the individual nature of transactions, but also the mechanism of generating net income, taking into account different types of reserves, the development of a scientific and methodical approaches to determining the level of influence of the tax burden on the bank's profit becomes relevant.

Solving this task will allow:

- to determine the level and direction of the impact of the income tax on the basic factor of the bank;

- to determine the quantitative independence between the tax rate and the relevant indicators of the bank's profit generation;

- Accept state-run scientific and managerial decisions on tax regulation of banking activities.

The conditions for the functioning of the banking sector are determined by a number of important factor, which is why there is an objective need to determine the type of competition that has developed in this sector, since this characteristic defines the key parameters of any market, namely: demand and supply functions, their inclination (for account of the value of the coefficient of elasticity) and the mechanism of pricing.

In addition, it should be noted that the level of concentration of the financial services market by other financial intermediaries creates an opportunity for the bank to transfer part of the tax burden to other economic entities. We note that the stages of development of the banking market and the level of its monopolization cause the variability of the application of various instruments of state tax policy. Identification of the type of competition in the market of banking services allows to formalize the functions of demand and supply of banking services, as well as with the help of mathematical transformation to reflect the cost of the bank, the features of the formation of reserves and their interdependence at each stages of the calculating of profit before taxation and, as a consequence, to determine the level of influence tax burden on the profit of the banking institution.

In conditions, for example, monopolistic competition, the functions (curve) of demand for banking services is declining. In order to formalize the demand functions of a bank, it is proposed to identifying its components, such as demand for loans (), intermediary services for which the commission () and the demand for other services () are paid. In general, the demand structure of the bank can be presented in the form of linear functions:

$$
\begin{aligned}
& L=l-l_{i} i_{l}-l_{t} T \\
& C=c-c_{f} f-c_{t} T \\
& A=a-a_{p} p-a_{t} T
\end{aligned}
$$

where 1, li, lt, c, cf, ct a, ap, at - parameters of regression equations that characterize the functions of demand for credit, commission and other services of the bank;

il - interest rate on loans;

f - fee for commission services provided by the bank;

$\mathrm{p}$ - payment for other services performed by the bank;

$\mathrm{T}-$ tax rate on profit.

The representation of the above-mentioned demand functions in the form of a linear regression equations with negative signs in the parameters is explained precisely by the direction of the demand curve for bank services in the conditions of monopolistic competition.

It should also be noted that the declining nature of the demand for banking services in general leads to the emergence of similar tendencies and for each separate components, that is, in fact, the demand for the above banking services increase with a decrease in price (id, $f$ and $p$ ), and they also have a negative impact on the profit tax rate $(\mathrm{t})$.

Proceeding from the logic of the formalization of the above-mentioned demand functions, the demand for deposit services by households can be written down by the following mathematical equations: 


$$
D=d+d_{i} i_{d}
$$

The positive parameter $d_{\mathrm{i}}$ reflect the elasticity of the general functions of demand in relation to the interest rate, that is, the dependence, which characterize the scale of changes in demand by changing the interest rate paid on deposit deposits by $1 \%$.

It is worth noting that after finding out the basic parameters that form the demand for banking services and the laws of their development, it is expedient to switch to the definition of the functions of aggregate operating expense, which it is quite logical to presents as the sum of fixed and variable operating expense. It should be noted that due to the fact that the variable costs are determined by the volume of services rendered, in order to formalize their overall expression, the volume of demand for a particular banking product with the average variable costs for the corresponding product was compared.

Thus, the total operating costs of the bank will be equal:

$$
O C=L v c_{L}+S v c_{S}+C v c_{C}+D v c_{D}+F
$$

Proceeding from the fact that one of the main features of the bank's activity is the formation of reserve funds in order to minimize possible crisis situations and ensure a high level of solvency, their formalization also has a special urgency. Consequently, the reserves () formed by the bank are proposed to be written as follows:

$$
R=R_{1}+R_{2}+R_{3}
$$

where $R_{1}$ - deductions to provisions for impairment of loans and funds in other banks;

$R_{2}$ - rovision for impairment of receivables and other financial assets;

$R_{3}$-deductions to provisions for liabilities.

Taking into account the defined components of operating expense and reserves, in expanded form, profit after tax can be presented by the following equations:

$$
P=\left(\left(i_{l} L-i_{d} D\right)+\left(C-C_{p}\right)+\left(A-A_{p}\right)-R\right) \times(1-T)
$$

where ${ }^{i_{l}}$ - interest rate on loans;

$i_{d}$ - interest rate on deposits;

$C_{p}$-expense of the bank related to the provision of commission services;

$A_{p}$ - expense of the bank related to the provision of other services;

$\mathrm{T}$ - tax rate on profit.

It is further expedient to develop a system of restrictions that will achieve the goal. Consequently, as the first limitation, it is proposed to apply the equality of balance, that is, the volume of all assets of the bank should be equal to its liabilities. More expanded this equality can be written using the following equations:

$$
L+A_{v}=Y+D+Z_{a}
$$

where $L_{-}$bank loans;

$$
\begin{aligned}
& A_{v} \text { - other bank assets (all assets excluding loans); } \\
& Y_{- \text {capital of the bank; }} \\
& D_{- \text {bank deposits; }} \\
& Z_{a_{-} \text {other liabilities of the bank (all liabilities, except for deposits). }}
\end{aligned}
$$


In addition to the equilibrium of balance that is inherent in each of the economic entities, the necessary condition for the functioning of banks is certain requirements for the adequacy of capital. This list of restrictions is characterized by a significant transformation and changes in time, but in general it can be presented as follows:

$$
\left\{\begin{array}{l}
N 1=R C \geq \delta \\
N 2=\frac{R C}{\left(\lambda_{1} G_{1}+\lambda_{2} G_{2}+\lambda_{3} G_{3}+\lambda_{4} G_{4}+\lambda_{5} G_{5}\right)-R_{a}-M-Q_{r}} \geq \rho \\
N 3=\frac{R C}{T A} \geq \sigma \\
N=(N 3-1)=\frac{R C}{D+Z_{a}} \geq \eta
\end{array}\right.
$$

where $N 1$ - standard minimum regulatory capital;

$R C$ - regulatory capital;

$\delta_{-} 120$ million UAH.;

$N 2$ - the standard of sufficiency (adequacy) of regulatory capital;

$G_{1}$ - cash; Bank metals, funds at the Central Bank; debt securities of state authorities refinanced by the central bank; accrued income on debt securities of state authorities refinanced by the central bank; accrued income on debt securities issued by the central bank; debt securities of state authorities; lending commitments that are provided to customers and for which the bank does not assume any risk; currency and bank metals to receive; bonds of the state mortgage institution, which are placed under the guarantee of the government; accrued income on bonds of the state mortgage institution, the placement of which is carried out under the guarantee of the government; loans and lending commitments granted to international financial institutions;

$G_{2}$ - short-term and long-term loans granted to public authorities and accrued income thereon;

$G_{3}$

- debt securities of local self-government bodies and accrued income thereon; cash on demand placed in a bank with a credit rating not lower than the investment grade and accrued income thereon; overnight deposits, other short-term deposits placed with a bank having an official credit rating not lower than the investment grade and accrued income thereon; overdraft, overnight and other short-term loans placed in a bank with an official credit rating not lower than the investment grade; accrued overdraft, overnight loans and other short-term loans in a bank that has an official credit rating of not lower than the investment grade and accrued income thereon; currency and bank metals purchased at spot positions in a counterparty bank in a bank that has an official credit rating not lower than the investment grade;

$G_{4}$ - cash on demand in other banks that are not members of the investment grade and accrued income thereon; overnight deposits placed in other banks that are not in the investment grade; short-term and long-term loans granted to local self-government bodies and their accrued income; guarantee deposits with other banks (covered); lending commitments issued to banks; currency and bank metals purchased under forward contracts; assets to receive; currency and bank metals purchased at spot positions in a counterparty bank that does not belong to the investment grade; overnight loans that are provided to other banks that do not belong to the investment grade; currency and bank metals to obtain under other option contracts; discount / premium before receiving forward currency contracts; hedged interest income of future periods in foreign currency; future hedged costs; mortgage loans granted to individuals in the national currency and fully secured by pledges of real estate for residential purposes; mortgage bonds issued by the state mortgage institution;

$G_{5}$ - other assets that are not included in the previous four groups $\left(G_{1}, G_{2}, G_{3}, G_{4}\right)$;

$\lambda_{1}, \lambda_{2}, \lambda_{3}, \lambda_{4}, \lambda_{5}$ - weight coefficients of risk, each asset group

$G_{1}, G_{2}, G_{3}, G_{4}, G_{5}$, in accordance $1 ; 0,9 ; 0,8 ; 0,5 ; 0$;

$R_{a_{\text {- formed }}}$ reserves for active operations;

$M$ - the pledge of property rights; 
$Q_{r}$ - bonds of an internal state loan refinanced by the central bank and debt securities issued by the central bank, acquired through repo transactions;

$\rho-10 \%$;

$N 3$ - the ratio of regulatory capital to total assets; $T A_{-}$total assets;

$\sigma-9 \%$;

$N$ - normative ratio of regulatory capital to liabilities;

$\eta_{-} 10 \%$.

The task of maximizing the bank's profits after taxation in a monopolistic competition is a classic optimization problem (the problem of conditional extremum). Formally, the problem statement in this case is proposed by summing the original problem into a problem on an unconditional extremum based on the application of the Lagrange multiplier method (Rudin, 1976). This approach involves the use of a differential calculus apparatus in order to quantify the variables of management that more closely ensure the achievement of the maximum value of the bank's profit after tax.

Thus, the fiscal impact of corporate profit tax on the choice of bank capital structure can be presented as an optimization task (in this study of maximization):

$$
\max _{i_{d}, i_{l}, t} P=\max _{i_{d}, i_{l}, t}\left(\left(i_{l} L-i_{d} D\right)+\left(C-C_{p}\right)+\left(A-A_{p}\right)-R\right) \times(1-T)
$$

The following restrictions, which determine the conditions for the operation of the banking institution:

$$
\left\{\begin{array}{l}
A_{v}+L=Y+D+Z_{a} \\
\left\{\begin{array}{l}
N 1=R C \geq \delta \\
N 2=\frac{R C}{\left(\chi_{1} G_{1}+\chi_{2} G_{2}+\chi_{3} G_{3}+\chi_{4} G_{4}+\chi_{5} G_{5}\right)-R_{a}-M-Q_{r}} \geq \rho \\
N 3=\frac{R C}{T A} \geq \sigma \\
N=(N 3-1)=\frac{R C}{D+Z_{a}} \geq \eta
\end{array}\right.
\end{array}\right.
$$

It is possible to develop a model considering the four capital constraints, too, as variable control, since the third equations takes into account aggregate assets ( $T A$ ), and the fourth volume of commitment ( $D+Z_{a}$ ).

At the same time, it should be noted that the formation of an expanded system, in our case, would only complicate the calculations and would have no decisive influence on the revealed patterns. In the solution of the tasks it is expedient to state only the necessity of the fulfillment of all these requirements. Taking into account the integral complex of these restrictions is relevant in case of determining the priority and degree of influence of the relevant factors on the profit of the bank, which in our case is not a goal. The proposed form of presentation of the investigated scientific and methodological approach is quite sufficient in order to determine the level of influence of the tax burden on the profit of the bank. Thus, the first stage of the practical implementation of the Lagrange multiplier method in the context of this study involves the construction of the Lagrange functions, which takes the form of the following relation:

$$
\begin{aligned}
& L\left(i_{d}, i_{l}, t, \lambda_{1}, \lambda_{2}, \lambda_{3}, \lambda_{4}, \lambda_{5}\right)=\left(\left(i_{l} L-i_{d} D\right)+\left(C-C_{p}\right)+\left(A-A_{p}\right)-R\right) \times(1-T)+ \\
& +\lambda_{1}\left(A_{v}+L-D-Z_{a}-Y\right)+\lambda_{2}(-R C+\delta)+ \\
& +\lambda_{3}\left(-\frac{R C}{\left(\chi_{1} G_{1}+\chi_{2} G_{2}+\chi_{3} G_{3}+\chi_{4} G_{4}+\chi_{5} G_{5}\right)-R_{a}-M-Q_{r}}+\rho\right)+ \\
& +\lambda_{4}\left(-\frac{R C}{T A}+\sigma\right)+\lambda_{5}\left(-\frac{R C}{D+Z_{a}}+\eta\right)
\end{aligned}
$$

where $\lambda_{1}, \lambda_{2}, \lambda_{3}, \lambda_{4}, \lambda_{5}$ - Lagrange multipliers that act as parameters of the Lagrange functions and allow the restriction of the target functions to be introduced. 
Given the ratio above $L=l-l_{i} i_{l}-l_{t} T_{\text {та }} D=d-d_{i} i_{d}$, the functions can be written as follows:

$$
\begin{aligned}
& L\left(i_{d}, i_{l}, t, \lambda_{1}, \lambda_{2}, \lambda_{3}, \lambda_{4}, \lambda_{5}\right)=\left(\left(i_{l} L-i_{d} D\right)+\left(C-C_{p}\right)+\left(A-A_{p}\right)-R\right) \times(1-T)+ \\
& +\lambda_{1}\left(A_{v}+l-l_{i} i_{l}-l_{t} T-d+d_{i} i_{d}-Y-Z_{a}\right)+\lambda_{2}(-R C+\delta)+ \\
& +\lambda_{3}\left(-\frac{R C}{\left(\chi_{1} G_{1}+\chi_{2} G_{2}+\chi_{3} G_{3}+\chi_{4} G_{4}+\chi_{5} G_{5}\right)-R_{a}-M-Q_{r}}+\rho\right)+ \\
& +\lambda_{4}\left(-\frac{R C}{T A}+\sigma\right)+\lambda_{5}\left(-\frac{R C}{D+Z_{a}}+\eta\right)= \\
& =\left(\left(i_{l}\left(l-l_{i} i_{l}-l_{t} T\right)-i_{d}\left(d-d_{i} i_{d}\right)\right)+\left(C-C_{p}\right)+\left(A-A_{p}\right)-R\right) \times(1-T)+ \\
& +\lambda_{1}\left(A_{v}+l-l_{i} i_{l}-l_{t} T-d+d_{i} i_{d}-Y-Z_{a}\right)+\lambda_{2}(-R C+\delta)+ \\
& +\lambda_{3}\left(-\frac{R C}{\left(\chi_{1} G_{1}+\chi_{2} G_{2}+\chi_{3} G_{3}+\chi_{4} G_{4}+\chi_{5} G_{5}\right)-R_{a}-M-Q_{r}}+\rho\right)+ \\
& +\lambda_{4}\left(-\frac{R C}{T A}+\sigma\right)+\lambda_{5}\left(-\frac{R C}{D+Z_{a}}+\eta\right)
\end{aligned}
$$

Since the variable management of the problem of maximizing profit after taxation is the interest rates on deposits and loans and the rate of income tax, therefore the next step in the implementation of the proposed approach is the definition of partial derivatives of the Lagrange functions in terms of these variables, as well as equating them to zero.

The solution of the system allows to determine the ratio of the quantitative estimation of variable management, whose achievement ensures maximization of the profit of the bank after taxation. In addition, the calculation formulas describe the marginal productivity of interest rates on deposits and loans, and the rates of tax on the profit of the bank. Consequently, we consider the sequence of expression steps from equations of the system of dependencies: rates of income tax on interest rates on deposits and loans; respectively, the interest rate on loans (deposits) from the tax rate on profit and interest rate on deposits (loans).

The solution of the system allows to determine the ratio of the quantitative estimation of variable management, whose achievement ensures maximization of the profit of the bank after taxation. In addition, the calculation formulas describe the marginal productivity of interest rates on deposits and loans, and the rates of tax on the profit of the bank. Consequently, we consider the sequence of expression steps from equations of the system of dependencies: rates of income tax on interest rates on deposits and loans; respectively, the interest rate on loans (deposits) from the tax rate on profit and interest rate on deposits (loans).

$$
\left\{\begin{array}{l}
\frac{\partial L}{\partial i_{d}}=\left(-d+2 d_{i} i_{d}\right) \times(1-T)+\lambda_{1} d_{i}=0 \\
\frac{\partial L}{\partial i_{l}}=\left(l-2 l_{i} i_{l}-l_{t} T\right) \times(1-T)-\lambda_{1} l_{i}=0 \\
\frac{\partial L}{\partial t}=-l_{i} i_{l} \times(1-T)-\left(\left(i_{l} L-i_{d} D\right)+\left(C-C_{p}\right)+\left(A-A_{p}\right)-R\right)-\lambda_{1} l_{t}=0 \\
\frac{\partial L}{\partial \lambda_{1}{ }^{*}}=A_{v}+l-l_{i} i_{l}-l_{t} T-d+d_{i} i_{d}-Y-Z_{a}=0 \\
\frac{\partial L}{\partial \lambda_{2}{ }^{*}}=-R C+\delta=0 \\
\frac{\partial L}{\partial \lambda_{3}{ }^{*}}=-\frac{R C}{\left(\chi_{1} G_{1}+\chi_{2} G_{2}+\chi_{3} G_{3}+\chi_{4} G_{4}+\chi_{5} G_{5}\right)-R_{a}-M-Q_{r}}+\rho=0 \\
\frac{\partial L}{\partial \lambda_{4}{ }^{*}}=-\frac{R C}{T A}+\sigma=0 \\
\frac{\partial L}{\partial \lambda_{5}{ }^{*}}=-\frac{R C}{D+Z_{a}}+\eta=0
\end{array}\right.
$$


First, we shall express from the first equations of a system the parameter $\lambda_{1}$,whose value depends directly on the variable of the tax rate management of the bank:

$$
\lambda_{1}=-\frac{(T-1)\left(d-2 d_{i} i_{d}\right)}{d_{i}}
$$

In addition, the above equations describes the marginal cost (elasticity) of liabilities (liabilities), that is, reflect the rate of increase in the value of liabilities (liabilities), depending on the growth (decrease) of the level of interest rate on deposits on $1 \%$.

Secondly, we will express from the second equations of the system the same parameter as determined by the bank's credit policy, but, unlike the ratio, which reflect the linear dependence of the parameter under consideration, characterize the dependence in the form of a second degree polynomial (that is, an increase in the tax rate on profit to a certain limit leads to a decrease, the excess of which is accompanied by a changes in the trend):

$$
\lambda_{1}=\frac{(T-1)\left(2 i_{l} l_{i}-l+l_{t} T\right)}{l_{i}}
$$

Alongside let's note that the given equations characterize the marginal cost (elasticity) of assets (income), that is, reflect the growth rate of the value of assets (income), depending on the growth (decrease) of the level of interest rate on loans for $1 \%$.

Third, equating the ratio we obtain the quantitative relationship between the three considered variables of control:

$$
-\frac{(T-1)\left(d-2 d_{i} i_{d}\right)}{d_{i}}=\frac{(T-1)\left(2 i_{l} l_{i}-l+l_{t} T\right)}{l_{i}}
$$

Fourthly, we will express the value of the tax rate on the bank's profit from interest rates on deposits and loans, using which determines the level of the said variable management, provided the equality of the marginal value of assets and liabilities of the bank is equal. As a result of calculations, we obtain two value of the tax rate on profit:

«1», which involves maximizing the profit after the bank's taxation at the level of $\mathrm{T}=100 \%$, which has no economic sense, and therefore can not be accepted as the optimal value of the variable management; in the form of a ratio:

$$
T\left(i_{d}, i_{l}\right)=-\frac{d l_{i}-d_{i} l-2 d_{i} i_{d} l_{i}+2 d_{i} i_{l} l_{i}}{d_{i} l_{t}}
$$

Fifthly, if we take as parameters of the size of the tax rate on the profit of the bank and the interest rate on deposits, we obtain the ratio of the quantitative estimation of the level of interest rate on loans:

$$
i_{l}\left(T, i_{d}\right)=-\frac{d l_{i}+d_{i} l+2 d_{i} i_{d} l_{i}-d_{i} l_{t} T}{2 d_{i} l_{i}}
$$

The analysis of the formula allows us to conclude on the impact of the rate of tax on bank profits on the formation of interest rate on loans: between these value there is a direct proportional dependence, that is, the growth rate of income tax is accompanied by an increase in interest rates on loans, because the value is in the numerator ratio. Sixth, using the ratio, we determine the dependence of the interest rate on deposits on the bank's profit tax rate and the bank's credit policy in the form of the following formula:

$$
i_{d}\left(t, i_{l}\right)=\frac{2 d_{i} i_{l} l_{i}+d_{i} l_{t} T-d l_{i}-d_{i} l}{2 d_{i} l_{i}}
$$

A thorough study of the relationships of the above relationship allows us to ascertain the following aspects: the presence of a directly proportional relationship between such variable controls in terms of maximizing the bank's profit after tax as a rate of income tax banks and interest rate on deposits, which means an opportunity to increase (decrease) the level of interest rate on deposits due to increase (decrease) of the tax rate on profit. 
It should also be noted that an increase in the interest rate on deposits and loans occurs at a much faster pace than the increase in the value of the tax rate, which is quite logical and logical and can be justified by the following statements: firstly, the tax rate on profit is a more static value , since it acts as one of the tools of state policy, and therefore its constant increase can lead to destabilization of the macroeconomic situation by reducing business activity, outflow of investments and growth the level of loss of business entities; and secondly, the state, presented by authorized bodies of executive power, can influence the dynamics of changes in interest rates on loans and deposits mainly through changes in the discount rate, and the direct fixing of rates for a particular financial and credit institution of this type is the authority of the commercial banks themselves and is carried out on their discretion, which is why credit (deposit) rates are more dynamic than the tax rate on profit; Thirdly, the formation of interest rates on loans and deposits of commercial banks is influenced by a number of factors, both subjective and objective, both internal and external, whereas the formation of the tax rate on profits is carried out centrally by the authorized bodies of state power and, it is worth it is positive that the stability of tax rates is positive and their changes only for the purpose of anti-cyclical regulation, while the volatility of credit and deposit rates is quite a natural phenomenon that may be caused by fluctuations in the market situation, changes in the bank's pricing policy, etc. As a conclusion on the meaning of the developed model, it can be noted that the application of the Lagrange multiplier method in order to maximize the profit of a bank after taxation by adjusting the rate of tax on bank profits, as well as interest rates on loans and deposits, allows:

- ensure achievement of the maximum value of the determined target functions taking into account restrictions on equivalence of balance and capital requirements;

- determine the optimal value of management variables, that is, the value of the rate of income tax of banks, interest rates on loans and deposits, which allow obtaining the maximum level of profit of the bank after taxation;

- quantify the relationship between estimates of the tax, credit and deposit policies of the bank;

- determine the marginal productivity of both interest rates on deposits and loans, both the income tax rate and the marginal cost (elasticity) of assets (income) and liabilities (liabilities) of the bank, which may act as a very effective tool for managing these value.

\section{Conclusions}

The developed model, on condition of availability to the actual data of the functioning of the banking system, allows tax optimization of commercial banks at the state level, since it allows one to determine the level of tax rates on profit, rates on loans and deposits, the value of which would allow commercial banks to receive maximum profit after tax, which would positively affect the indicators of profitability and business activity of the banking sector, would make it more stable, and, consequently, racks $m$ to the destructive impact of crisis processes at the supranational level, which in turn would allow commercial banks to perform their functions more effectively, the main of which is the optimal redistribution of financial resources between donors and recipients, thus supporting the corporate sector, which is the main producer of value added and, accordingly, promote the macroeconomic stability of the state as a whole, ensure its dynamic and steady development through permanent GDP growth.

Since passage of the law, community banks have maintained their share of all commercial banks, but have seen further significant declines in their aggregate share of banking industry assets. The influence of tax burden on budget tax revenues and production capacity can be realized in two different ways. On the one hand, tax burden influences production technologies, effective usage of resources that accordingly will be depicted on the production capacity and, on the other hand, the change of tax burden influences budget tax revenues that will be depicted on the economic activity.

The tax burden influences not only the budget revenues, but investments, demand and supply, prices and others. All this has direct as well as indirect influence on the economic activity and production capacity. In the concept of tax burden the important fact is the connection of tax burden with the economic activity and production capacity.

Tax burden is undoubtedly one of the key indicators that characterize the tax system of the country and its fiscal policies. Tax burden shows the impact of taxes on the economy in general, and describes the impact of tax payments on reducing the taxpayers' profits. Economists identify a number of factors that affect the amount of tax burden. But it is important to classify the factors affecting the amount of tax burden according to the possibilities of enterprise's management to control the impact of these factors during the process of the tax planning concept implementation. Managers of enterprises must control the internal factors of influence on tax burden to reduce the tax burden on their business. 


\section{References}

1. Amando M. T. Jr. The tax-exempt status of the central bank in the Philippines. Retrieved from: http://www.bis.org/ publ/bppdf/bispap20s.pdf.

2. Baker D. Ken Rogoff Misses the Boat on Financial Speculation Taxes. Retrieved from: http://www.cepr.net/index.php/blogs/cepr-blog/ken-rogoff-misses-the-boat-on-financial-speculation-taxes. Title from the screen.

3. Baker D. Responses to Criticisms of Taxes on Financial Speculation. Retrieved from: http://www.cepr.net/documents/publications/ftt-criticisms-2010-01.pdf. - Title from the screen.

4. Benchmarking Financial Systems Around the World (2012). World Bank Policy Research Working Paper 6175, World Bank, Washington, D. C., 203. Retrieved from: http://data.worldbank.org/data-catalog/globalfinancial-development.

5. Espinoza-Wega Marko A. (2001). On Business Cycles and Countercyclical Policies. Federal Reserve Bank of Atlanta Economic Review. Fourth Quarter. 11.

6. Financial Sector Taxation. The IMF's Report to the G-20 and Background Material. -: http://www.imf.org/external/np/seminars/eng/2010/paris/pdf/090110.pdf.

7. Hainsworth R. (2001). The taxation of Russian banks. Working Papers of the Research Centre for East European Studies, Bremen., 30, 27.

8. Hau H. (2006). The Role of Transaction Costs for Financial Volatility: Evidence from the Paris Bourse Journal of the European Economic Association., 4(4), 862-890.

9. Hawkins J. Central bank balance sheets and fiscal operations. Retrieved from: http://home.student.bi.no/ s0514465/Central\%20Bank\%20Balance\%20Sheet\%20and\%20Fiscal\%20Operati ons.pdf.

10. How Should a Central Bank Be Treated for Tax Purposes? International Monetary Fund. Retrieved from: http://www.imf.org/external/np/leg/ tlaw/2007/eng/cbtt.pdf.

11. Jetin B. Financing development with global taxes : Fiscal revenues of a currency transaction tax. Retrieved from: http://gesd.free.fr/jetin39.pdf.

12. Ricotti G. (2010). La pressione fiscale gravante sul sistema bancario: questioni metodologiche ed evidenze empiriche. Questioni di Economia e Finanza, 80.

13. Schulmeister S. A (2009). General Financial Transaction Tax: A Short Cut of the Pros, the Cons and a Proposal WIFO Working Papers, 344. Retrieved from: http://www.wifo.ac.at/wwa/servlet/wwa.upload. DownloadServlet/bdoc/WP_2009_344\$.PDF.

14. Schulmeister S. A (2005). General Financial Transaction Tax. Motives, Revenues, Feasibility and Effects Structures of the taxation systems in the European Union. Luxembourg : Office for Official Publications of The European Commission, 274-275.

15. Tax Contribution of The Financial Sector. European Comission. Taxation and Customs Union. Retrieved from:http://ec.europa.eu/taxation_customs/resources/documents/taxation/other_taxes/financial_sector/ fact sheet/ tax-contribution-fin-sector.pdf.

16. Taxing Banks [Electronic resource] / A report submitted to the International Monetary Fund. - Mode of Access: http://www.taxresearch.org.uk/Documents/IMFTaxingBanks.pdf. - Title from the screen.

17. The Financial Crisis. Reform and Exit Strategies. OECD.: Retrieved from: http://www.oecd.org/regreform/sectors /43091457.pdf.

18. Tobin J. A. (1978). Proposal for International Monetary Reform.Eastern Economic Journal (Eastern Economic Association), 3-4, 153-159.

19. Rudin, Walter (1976). Principles of Mathematical Analysis (3rd ed.) (PDF). New York: McGraw-Hill, 113. 